\title{
Dressing-related trauma: clinical sequelae and resource utilization in a UK setting
}

This article was published in the following Dove Press journal:

ClinicoEconomics and Outcomes Research

28 April 2014

Number of times this article has been viewed

\section{Bruce Charlesworth' \\ Claire Pilling' \\ Paul Chadwick ${ }^{2}$ \\ Martyn Butcher ${ }^{3}$}

'Adelphi Values, Macclesfield, ${ }^{2}$ Salford Royal Foundation Trust, Salford, ${ }^{3}$ Northern Devon Healthcare Trust, Devon, UK
Correspondence: Bruce Charlesworth Adelphi Mill, Bollington, Cheshire, SKIO 5JB, UK

Tel +44 I625 578870

Email bruce.charlesworth@adelphivalues. com
Background: Dressings are the mainstay of wound care management; however, adherence of the dressing to the wound or periwound skin is common and can lead to dressing-related pain and trauma. Dressing-related trauma is recognized as a clinical and economic burden to patients and health care providers. This study was conducted to garner expert opinion on clinical sequelae and resource use associated with dressing-related trauma in a UK setting.

Methods: This was an exploratory study with two phases: qualitative pilot interviews with six wound care specialists to explore dressing-related trauma concepts, sequelae, and resource utilization; and online quantitative research with 30 wound care specialists to validate and quantify the concepts, sequelae, and resource utilization explored in the first phase of the study. Data were collected on mean health care professional time, material costs, pharmaceutical costs, and inpatient management per sequela occurrence until resolution. Data were analyzed to give total costs per sequela and concept occurrence.

Results: The results demonstrate that dressing-related trauma is a clinically relevant concept. The main types of dressing-related trauma concepts included skin reactions, adherence to the wound, skin stripping, maceration, drying, and plugging of the wound. These were the foundation for a number of clinical sequelae, including wound enlargement, increased exudate, bleeding, infection, pain, itching/excoriation, edema, dermatitis, inflammation, and anxiety. Mean total costs range from $£ 56$ to $£ 175$ for the complete onward management of each occurrence of the six main concepts.

Conclusion: These results provide insight into the hidden costs of dressing-related trauma in a UK setting. This research successfully conceptualized dressing-related trauma, identified associated clinical sequelae, and quantified resource utilization associated with a typical occurrence of each trauma concept. Further research is warranted into dressing-related trauma and the associated costs.

Keywords: trauma, dressings, wounds, cost, resource use

\section{Introduction}

Wounds may be caused by a variety of mechanisms and can be acute or chronic. ${ }^{1}$ Acute wounds are generally the result of deliberate or accidental trauma, and progress through the healing process within an expected amount of time ( 4 weeks) without complication. ${ }^{1,2}$ Chronic wounds fail to heal in the expected time frame and are usually associated with comorbidities (eg, diabetes), poor nutrition, medications that may delay healing, altered body function (eg, venous insufficiency), or inappropriate dressing selection. ${ }^{2}$

The management of acute and chronic wounds can be a complex and difficult task. ${ }^{1}$ Wound management priorities include optimizing the wound environment, by treating underlying causes or removing any causative agent, to promote healing 
and prevent complications. ${ }^{1,3}$ Dressings are the mainstay of wound care management, and many have been developed to provide a moist environment for healing, to promote re-epithelialization and wound closure, and to absorb blood and tissue fluids. ${ }^{4}$ Dressings are, however, usually held in place with integral adhesive layers or retention bandages. ${ }^{5,6}$ Adherence of the dressing to the wound or periwound skin is common, and can lead to complications such as dressingrelated pain and dressing-related trauma. ${ }^{6}$

Pain is a significant problem with all types of wounds. ${ }^{6}$ The highest levels of pain are associated with wound and periwound damage occurring during dressing changes. ${ }^{6}$ The requirement for management of dressing-related pain is acknowledged and documented within the field of tissue viability. ${ }^{7}$ A number of international best practice statements and guidelines for managing wound and dressing-related pain have recently been published. ${ }^{7,8}$ In comparison, recognition of and guidance on dressing-related trauma are lacking, despite an international survey that aimed to identify practitioners' primary considerations at dressing change finding that respondents from seven of the eleven countries ranked preventing trauma as the most important factor to consider when changing a dressing. ${ }^{9}$

Dressing-related trauma includes not only trauma to the wound and periwound skin, such as skin stripping, maceration, and skin reactions, but also associated clinical sequelae, such as inflammation, edema, dermatitis, and pain. ${ }^{10,11}$ Dressing-related trauma can also increase the size of wounds and delay healing. ${ }^{12}$ Each of these sequelae can have an adverse effect on patients. ${ }^{12}$

Dressing-related trauma is not only a clinical burden to patients and health care professionals, but it is also a cost burden. ${ }^{13}$ It is widely recognized that wound care treatment and prevention consume large quantities of resources, including pharmaceuticals, materials, and nursing time. ${ }^{14}$ Furthermore, the financial burden of chronic wounds will continue to rise as the population ages and there is an increase in diseases such as obesity and diabetes. ${ }^{15}$ These factors, combined with budget-constrained health care systems, mean that resource use associated with wound care is becoming a significant area of focus for health care budget holders. It is in this context that the following study was conducted to garner expert opinion on clinical sequelae and resource use associated with dressing-related trauma in a UK setting. The objective of the study was primarily exploratory and these data do not represent a formal burden of illness study.

\section{Materials and methods Overall study methodology}

The study was exploratory in nature and consisted of two phases. The first phase included qualitative interviews with a small group of wound care specialists. The second phase included an online quantitative questionnaire with a wider sample of wound care specialists.

\section{Phase I: qualitative interviews}

Trauma-concept elicitation interviews were conducted in November 2011. UK-based wound care specialists were recruited via email, with eligibility assessments conducted prior to email contact. Inclusion criteria were: active involvement in wound care management in the last 6 months, an understanding and appreciation of the health care resource use associated with wound care management, and more than 6 months of experience in active wound management.

One-to-one interviews of approximately 30 minutes were conducted via telephone. The interview technique was semistructured to allow for qualitative probing and prompting techniques. The flow of the qualitative interviews is presented in Figure 1.

The interviews were designed to elicit trauma concepts, sequelae, and resources that were of the highest importance and of most relevance to experts in the field of wound care. The interviews were conducted sequentially and were continued until no new themes/data emerged. All interviews were digitally recorded for categorization, and the outcomes of the interviews were used to optimize and guide the design of the quantitative online questionnaire for the second phase of the research.
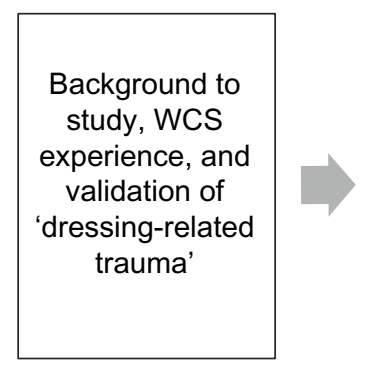

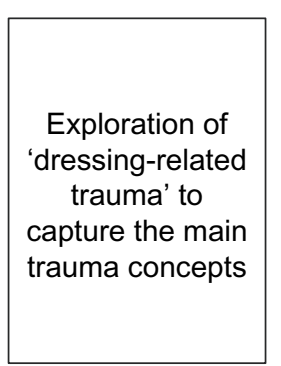

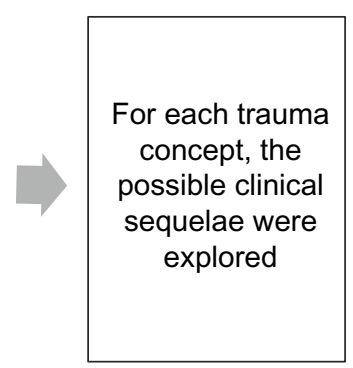

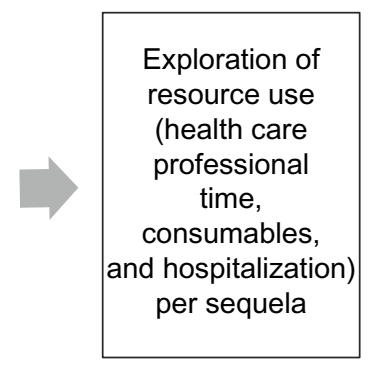

Figure I Qualitative interview structure. Abbreviation: WCS, wound care specialists. 


\section{Phase 2: quantitative online questionnaire}

The second phase of the research involved a questionnairebased survey conducted between October 8, 2012 and November 5, 2012. UK-based wound care specialists were recruited via health care professional e-research communities. Wound care specialists involved in the first phase of qualitative interviews were also recruited. Wound care specialists were contacted via telephone and provided informed consent. Wound care specialists were then invited by email to complete the online questionnaire.

Online research is suitable for quantitative data collection because it ensures consistency in data collection (as no interviewer bias is introduced) and allows for real-time routine checks to ensure logical answers. ${ }^{16}$ Furthermore, online research also provides access to individuals with whom it would be difficult to conduct research through other channels. ${ }^{16}$ Electronic data collection was therefore considered appropriate for this exploratory study.

Wound care specialists completed a screening phase to confirm eligibility for study inclusion. Inclusion criteria were: active involvement in wound care management in the last
6 months, understanding of the concept of "dressing-related trauma", understanding and appreciation of the health care resource use associated with the treatment of dressing-related trauma, and more than 6 months of experience in active wound management.

A target of 30 complete responses from a sample of tissue viability nurses, clinical nurse specialists, podiatrists, and dermatologists was set. This sample size of 30 was considered sufficient for exploration of the data, and quotas were applied to each specialty (tissue viability nurses $\sim 30 \%$, clinical nurse specialists $\sim 30 \%$, podiatrists $\sim 20 \%$, and dermatologists $\sim 20 \%$ ) to ensure a representative sample of each specialist group. This study was not powered to calculate statistical significance. All respondents were anonymized and the study was completed in line with British Healthcare Business Intelligence Association legal and ethical guidelines. ${ }^{17}$ Wound care specialists were offered a small incentive for completion of the survey, which was in line with current market research guidelines.

The online questionnaire included three sections (see Table 1). The estimated total amount of time taken to complete the questionnaire was 35 minutes; however, wound care

Table I Structure of the online questionnaire

\begin{tabular}{|c|c|c|}
\hline Section & Relevance & Sample question \\
\hline \multirow{2}{*}{$\begin{array}{l}\text { I. Dressing- } \\
\text { related }\end{array}$} & \multirow[t]{2}{*}{ Validation of phase one concepts } & "In your experience of managing wound patients, have you ever observed \\
\hline & & [insert trauma concept] as a consequence of the wearing or removal of a dressing?" \\
\hline trauma & Elicitation of new concepts & "In your experience of managing wound patients, have you ever observed any other \\
\hline & & trauma which occurred as a consequence of the wearing or removal of a dressing?" \\
\hline \multirow{6}{*}{$\begin{array}{l}\text { 2. Clinical } \\
\text { sequelae }\end{array}$} & Validation of clinical sequelae associated with & "As a result of [insert trauma concept] have you ever observed [insert sequela]?" \\
\hline & each concept in the first phase of the study & \\
\hline & Elicitation of any new clinical sequelae & "As a result of [insert trauma concept] have you ever observed any other clinical \\
\hline & associated with each concept & sequelae?" \\
\hline & \multirow[t]{2}{*}{ Incidence of each clinical sequela } & "In what percentage of patients with [insert trauma concept] is [insert sequela] \\
\hline & & a consequence?" \\
\hline \multirow{19}{*}{$\begin{array}{l}\text { 3. Management } \\
\text { of sequelae }\end{array}$} & \multicolumn{2}{|l|}{ Resource use associated with each sequela: } \\
\hline & \multirow[t]{2}{*}{ Time of health care professionals } & "In general, how long (in minutes) would health care professionals be directly involved \\
\hline & & in the complete onward management of [insert sequela]?" \\
\hline & \multirow[t]{5}{*}{ Materials } & "In general, would health care professionals use, or provide to the patient, \\
\hline & & [insert material] for the management of [insert sequela] due to dressing-related trauma?" \\
\hline & & "If yes, how much [insert material] would be used per application?" \\
\hline & & "In general, how many times would [insert material] be required \\
\hline & & (until the [insert sequela] has resolved)?" \\
\hline & \multirow[t]{7}{*}{ Therapeutics } & "In general, would health care professionals use, or provide to the patient, [insert \\
\hline & & pharmaceutical] for the management of [insert sequela] due to dressing-related trauma?" \\
\hline & & "If yes, what brand of [insert pharmaceutical] would be provided to a patient?" \\
\hline & & "What would the typical (singular) dosage of [insert pharmaceutical] be?" \\
\hline & & "What is the daily frequency of the stated dosage?" \\
\hline & & "How many days would a patient require treatment with [insert pharmaceutical] \\
\hline & & for (until x has resolved)?" \\
\hline & \multirow[t]{4}{*}{ Inpatient management } & "In general, would [insert sequela] due to dressing-related trauma, \\
\hline & & require additional in-patient management?" \\
\hline & & "If yes, what percentage of cases requires hospitalization?" \\
\hline & & "What is the additional length of hospital stay per episode (in days)?" \\
\hline
\end{tabular}


Table 2 Concepts and approved medical definitions

\begin{tabular}{|c|c|}
\hline Concepts & Medical definition \\
\hline Skin reaction & $\begin{array}{l}\text { Irritation, inflammation, excoriation, or other } \\
\text { skin changes (at or around the wound site) due to } \\
\text { wearing or changing of a dressing }\end{array}$ \\
\hline $\begin{array}{l}\text { Adherence } \\
\text { to wound }\end{array}$ & Dressing material sticking to wound or healing tissue \\
\hline Skin stripping & $\begin{array}{l}\text { Damage to the wound or periwound skin due to wearing } \\
\text { or changing of a dressing, usually adhesive-related }\end{array}$ \\
\hline Maceration & $\begin{array}{l}\text { Skin changes resulting from prolonged exposure } \\
\text { to moisture or wound exudate in a dressed wound }\end{array}$ \\
\hline Drying & $\begin{array}{l}\text { Skin or wound damage due to an overly dry dressing } \\
\text { environment }\end{array}$ \\
\hline $\begin{array}{l}\text { Plugging of } \\
\text { wound }\end{array}$ & $\begin{array}{l}\text { Damage to cavity wound caused by packing a } \\
\text { dressing material too tightly }\end{array}$ \\
\hline
\end{tabular}

specialists could log in and out of the questionnaire, if required. Limits for upper and lower entry values were included within the questionnaire to minimize erroneous values. Questionnaires were completed anonymously; however, responses could be tracked across the different specialties. The sequelae were considered independently of any particular concept to allow for quantification of each individual sequela (Figure 2).

\section{Health care professional time}

Data were collected on mean health care professional time per sequela occurrence until resolution (health care professional time $=$ mean time per occurrence). The average hourly wages of both a community nurse and a hospital-based nurse were used to calculate costs. ${ }^{18}$ The ratio of predominant setting of care was used to weight the wage costs. Data were analyzed to give health care professional time costs per sequela occurrence (Figure 2).

\section{Material consumption}

Data were collected on mean material usage per sequela occurrence until resolution (type of material $=$ mean unit size per occurrence * mean frequency of use per unit). Data on the unit cost of each of the materials were taken from the Wound Care Handbook, UK edition. ${ }^{19}$ Data were analyzed to give material costs per sequela occurrence (Figure 2).

\section{Pharmaceutical product usage}

Data were collected on mean pharmaceutical usage per sequela occurrence until resolution (brand of pharmaceutical $=$ mean

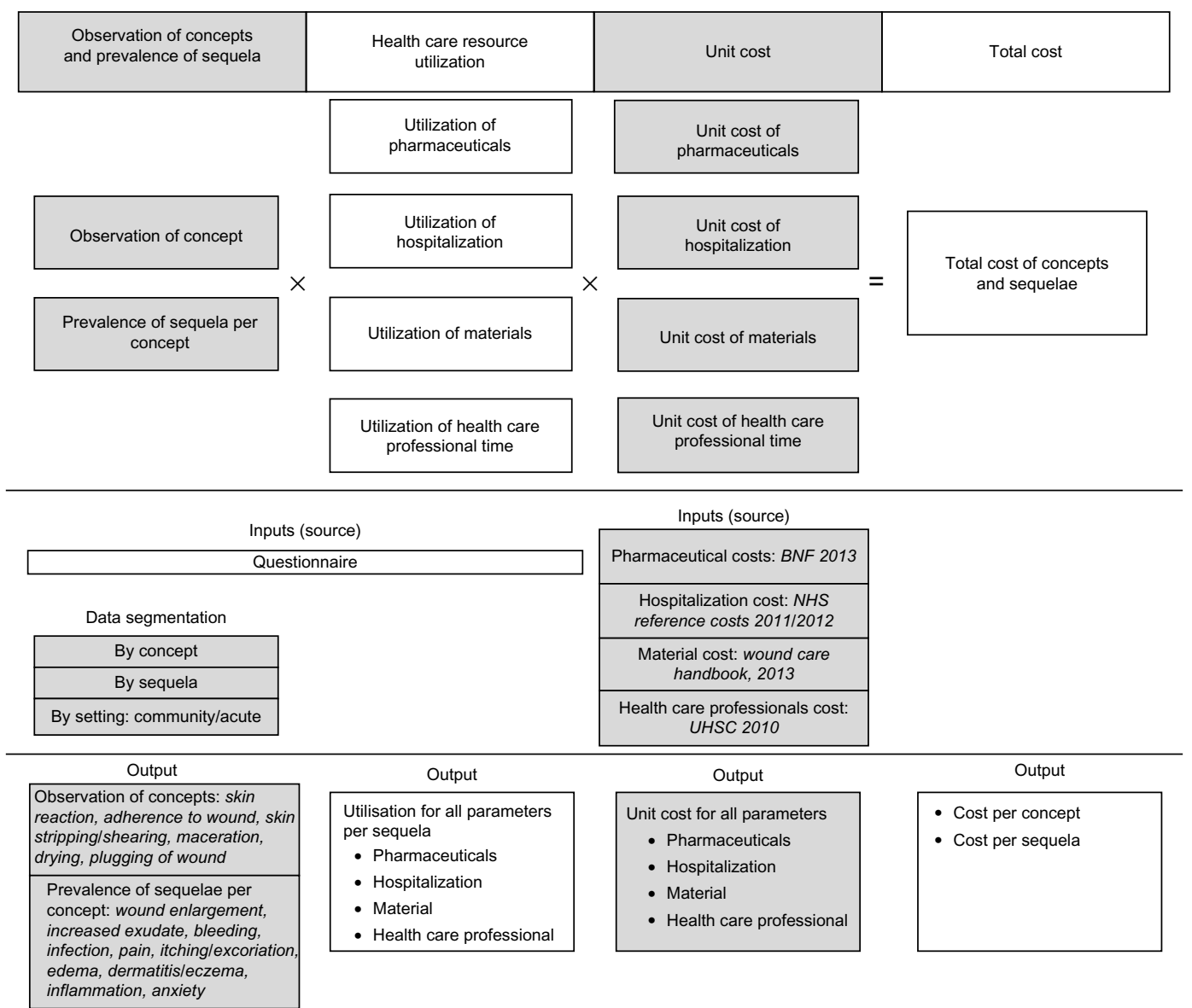

Figure 2 Conceptual design of the cost model. 
singular dosage * mean daily frequency of stated dosage * duration of use until resolution). Data on the unit cost of each of the pharmaceuticals were taken from the British National Formulary, UK edition. ${ }^{20}$ Data were analyzed to give pharmaceutical costs per sequela occurrence (Figure 2).

\section{Inpatient management}

Data were collected on inpatient management per sequela occurrence until resolution (inpatient management $=$ mean proportion of patients requiring inpatient management * length of inpatient management [in days]). These two figures, along with a bed-day cost of $£ 264^{21}$ were used to produce an expected inpatient cost per sequela occurrence.

These data were analyzed to give overall expected costs per sequela occurrence (see Figure 2 for cost model design). The expected cost of each sequela was then multiplied by the probability of occurrence within a particular concept. The sequelae occurrence costs were then added together per concept to provide a typical cost per concept occurrence. Data relating to delayed healing and use of preventative wound contact layers were also collected (data not presented in this publication).

The results were transferred into Microsoft Excel (2010). Standard descriptive analyses (means, percentages, and standard deviations) were performed. Data were cleaned using logical consistency checks against other respondent answers and sense checking against published guidance (eg, British National Formulary recommended guidance on dosage). Where a response may have ambiguous or incomplete data, assumptions were made based on other relevant complete responses. Only completed questionnaires of subjects who met the inclusion criteria were included in the analysis $(n=30)$. Because this was an exploratory study, no power calculations or statistical analyses were performed to determine significance.

\section{Results}

\section{Phase I: qualitative interviews}

A total of six interviews were completed before novel themes (concepts, sequelae, or management practices) ceased to emerge. Respondents included four tissue viability nurses, one principal podiatrist, and one dermatology specialist nurse.

All six wound care specialists indicated that "dressingrelated trauma" is a standardized medical term used to define wound trauma due to the wearing or removal of a dressing. Seven different types of trauma, ie, trauma concepts, were elicited (see Figure 3). Overall, four of six wound care specialists identified skin reaction, adherence to the wound, and skin stripping as trauma concepts elicited due to the wearing or removal of a dressing. Maceration was also mentioned by half of the wound care specialists $(n=3)$. Three further concepts were elicited at lower frequencies, including drying $(n=2)$, plugging of the wound $(n=1)$, and granulation of the wound cavity $(n=1)$.

A qualified UK medical practitioner (BC) reviewed each concept and one item ("granulation of the wound cavity") was deleted due to perceived repetition. A medical definition

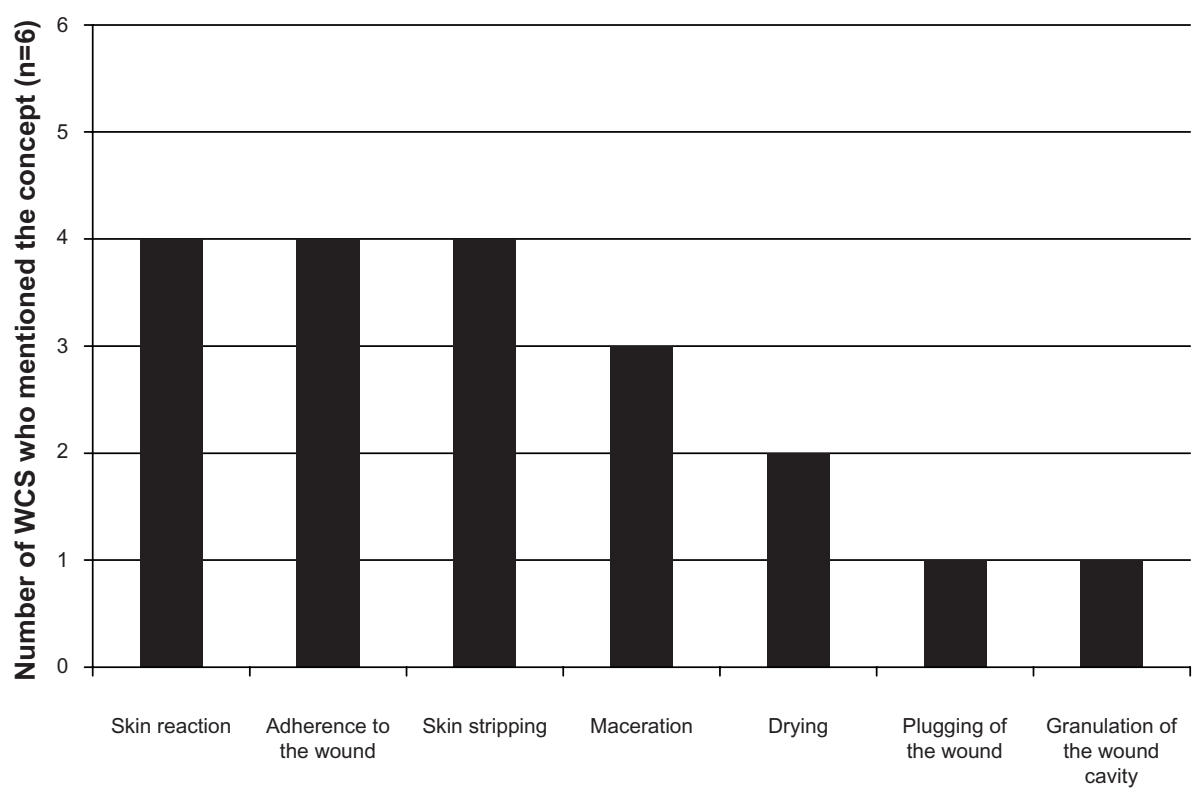

Figure 3 Trauma incurred as a result of wearing or removing a dressing. Abbreviation: WCS, wound care specialists. 


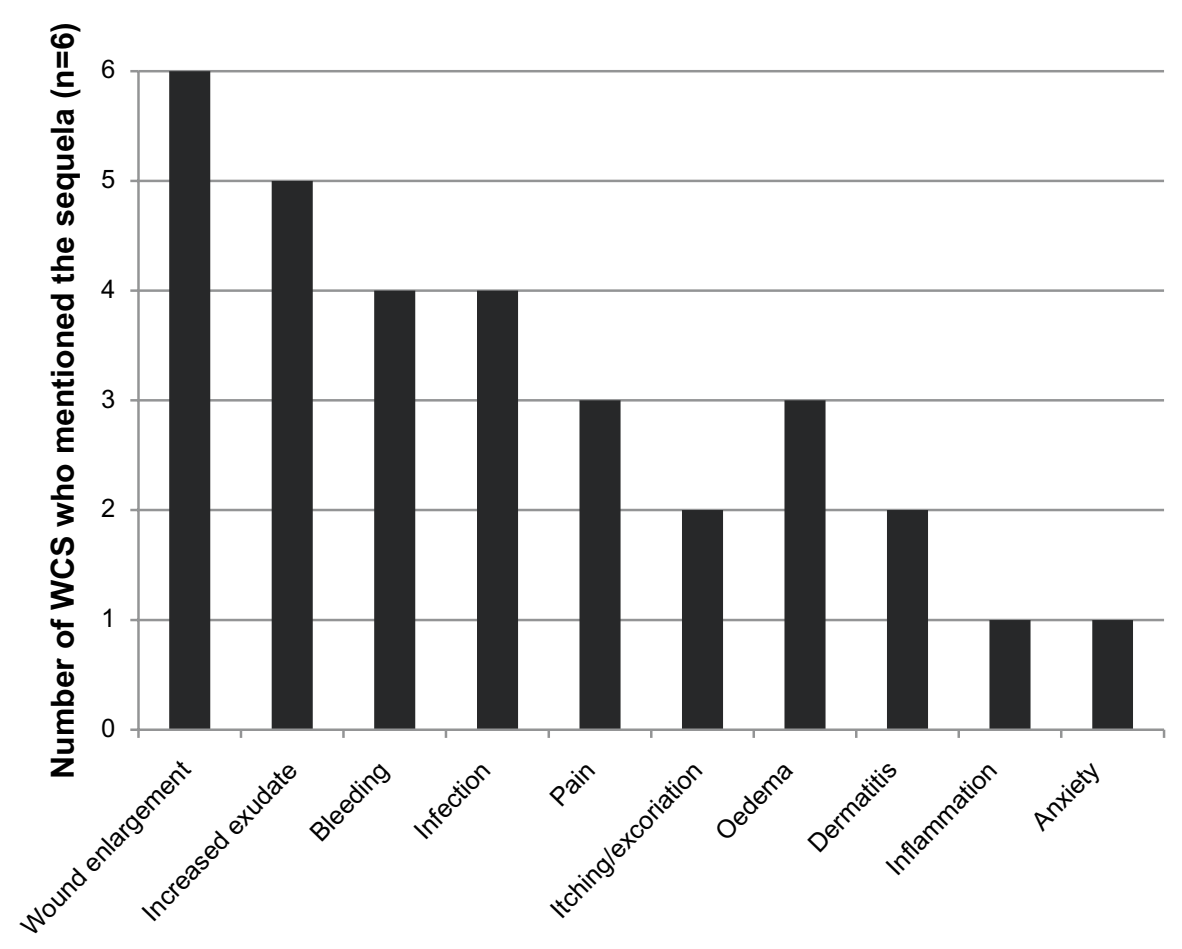

Figure 4 Clinical consequences of dressing-related traumas. Abbreviation: WCS, wound care specialists.

was developed and approved for the six final trauma concepts (Table 2).

Ten clinical consequences, or sequelae, of each of the concepts were elicited from the interviews. The most cited sequela was wound enlargement $(n=6)$; increased exudate $(n=5)$, bleeding $(n=4)$, and infection $(n=4)$ were also mentioned regularly (Figure 4). Further sequelae included pain, edema, itching/excoriation, dermatitis/eczema, inflammation, and anxiety.

The typical resource use associated with management of clinical sequelae was given by the wound care specialists. Typical resources included health care professional time, materials, pharmaceutical products, and other interventions (Table 3).

The results of the interviews were used to inform the design of the quantitative online questionnaire and to inform recruitment for the second phase of the study (ie, tissue viability nurses, podiatrists, and dermatologists were recruited because they were deemed to be "actively involved in wound care management"). Clinical nurse specialists were also targeted for inclusion in the second phase of the study because the aims of clinical nurse specialist practice include "advancing nursing practices, improving outcomes, and providing clinical expertise to holistically improve programs of care". ${ }^{22}$

The six final trauma concept definitions and all ten sequelae were deemed to be appropriate terms and were therefore included in the online questionnaire. Some nonconsumable items (scissors, towels, and aprons) were removed due to their reusable nature and unclear costs. Minor changes were also made to the material terminology to increase clarity and avoid misinterpretation; for example, the different types of dressings were combined under an umbrella term of "secondary dressings". Some pharmaceutical

Table 3 Resource utilization associated with sequelae management

\begin{tabular}{ll}
\hline Resource & Type \\
\hline Health care & Tissue viability nurses \\
professional & Podiatrists \\
time & Dermatologists \\
& General practitioners \\
& Vascular nurses \\
& Community nurses \\
& Plastic surgery nurses \\
Materials & Dressings (absorbent dressings, secondary \\
& dressings, bigger dressings, silver dressings) \\
& Surgical necessities (scissors, aprons, gloves, \\
& towels, gauze pads) \\
& Bandages \\
& Stockings \\
& Skin barriers \\
& Saline solution \\
& Analgesics \\
Pharmaceuticals & Antihistamines \\
& Antimicrobial creams \\
& Topical steroids \\
& Antibiotics \\
& Behavioral therapy (such as distraction techniques)
\end{tabular}


Table 4 Demographics of wound care specialists involved in the second phase of the research $(n=30)$

\begin{tabular}{|c|c|c|c|c|}
\hline Specialty & $\mathbf{n}$ & $\begin{array}{l}\text { NHS band } \\
\text { level range* }\end{array}$ & $\begin{array}{l}\text { Years spent in } \\
\text { active wound } \\
\text { care management, } \\
\text { mean (range) }\end{array}$ & $\begin{array}{l}\text { Setting } \\
\text { of care }\end{array}$ \\
\hline $\begin{array}{l}\text { Tissue viability } \\
\text { nurses }\end{array}$ & 8 & $6-8 b$ & $10.5(4-20)$ & $\begin{array}{l}8 \text { acute } \\
0 \text { community }\end{array}$ \\
\hline $\begin{array}{l}\text { Clinical nurse } \\
\text { specialists }\end{array}$ & 8 & $5-8 a$ & I4.4 (3.75-28) & $\begin{array}{l}0 \text { acute } \\
8 \text { community }\end{array}$ \\
\hline Podiatrists & 5 & $7-9$ & $11.9(2.5-20)$ & $\begin{array}{l}3 \text { acute } \\
2 \text { community }\end{array}$ \\
\hline Dermatologists & 9 & $3-9$ & I 3.7 (7.5-20) & $\begin{array}{l}9 \text { acute } \\
0 \text { community }\end{array}$ \\
\hline
\end{tabular}

Note: *current grading and pay system for all NHS staff, with the exception of doctors, dentists and some senior managers.

Abbreviation: NHS, National Health Service.

terminology was subdivided for improved detail; for example, "antihistamines" were subdivided into intravenous or oral methods of administration. The reference to behavioral techniques in the interviews (eg, distraction techniques) led to inclusion of a question relating to inpatient management in the online questionnaire.

\section{Phase 2: quantitative online questionnaire Demographic data}

A quota of 30 complete questionnaires was set; this total was reached within 4 weeks. Review of the completion rates and the limited amounts of anomalous data show that the questionnaire was well understood by the respondents. The demographic breakdown for the 30 wound care specialists involved in the quantitative online questionnaire is shown in Table 4. Respondents had been qualified for between 2.5-28 years and covered four specialties within the wound care setting at various National Health Service grades. The questionnaire also included demographics according to the predominant practice setting of care, with a third of all wound care specialists being based predominantly in the community.

\section{Dressing-related trauma concepts}

All 30 wound care specialists reported that both the wearing and removal of a dressing can have traumatic consequences. Each of the six original trauma types, or trauma concepts, was confirmed as relevant (Figure 5). All 30 respondents had observed skin reaction and skin stripping as a result of wearing or removing a dressing. Eight wound care specialists detailed additional concepts, of which only one (blistering) was considered truly novel and relevant for inclusion.

\section{Clinical sequelae}

Wound care specialists assessed whether the ten previously elicited clinical sequelae were typically associated with each

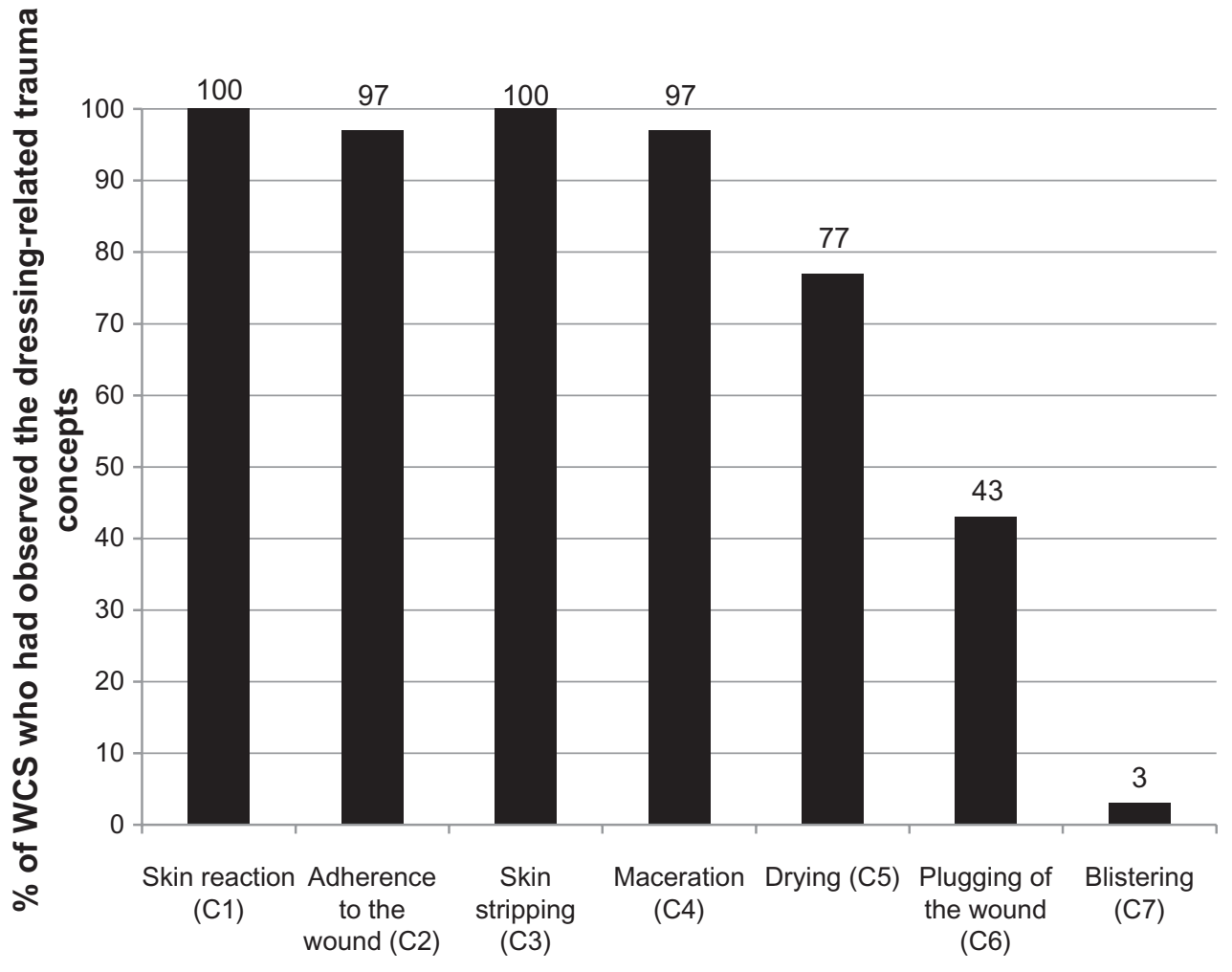

Figure 5 Proportion of WCS reporting each trauma concept.

Abbreviation: WCS, wound care specialists. 
of the trauma concepts, and if so how often. Any additional sequelae were also elicited. Cumulative results show that all of the original concepts were associated with all ten sequelae (Table 5).

The novel concept, "blistering", was associated with all sequelae except edema and dermatitis (Table 5). One novel sequela, "skin tear", was elicited from one wound care specialist as a result of adherence to the wound. This sequela was included in all further analyses of "adherence to the wound" because it was considered relevant and was not fully represented within the current sequelae. Of all of the sequelae, pain (S5), and anxiety (S10) were reported in the highest proportion of patients as a result of four of the six main concepts (Table 5).

\section{Expected cost per sequela occurrence}

Data were then collected on health care resource use, including health care professional time, consumables, and inpatient management per sequela occurrence.

\section{Health care professional time}

Cumulative results from the 30 wound care specialists show that all of the main sequelae were associated with health care professional time (Table 6). Health care professional time ranged from a mean of 17 minutes to 32 minutes, depending on the clinical sequela (data not shown). Infection (S4) and anxiety (S10) were associated with the greatest duration of health care professional time and hence were associated with the highest health care professional costs (Table 6).

\section{Material costs}

Cumulative results from the 30 wound care specialists show that all of the main sequelae were associated with use of all seven materials (Table 7). Materials included those elicited in the first phase of the research, ie, secondary dressings, skin barriers, stockings, bandages, gauze pads, disposable gloves, and saline solution. No new material types were elicited in the second phase of the study. Gauze pads and stockings were high contributors to the material costs. Notably, the cost of dressings was relatively low in all sequelae (Table 7). The per sequela material costs were higher than the health care professional time costs per sequela. Wound enlargement (S1) and increased exudate (S2) were associated with particularly high total material costs (Table 7). Skin tear (S11), the novel sequela reported by one wound care specialists, was associated with a typical material cost of $£ 16.71$.

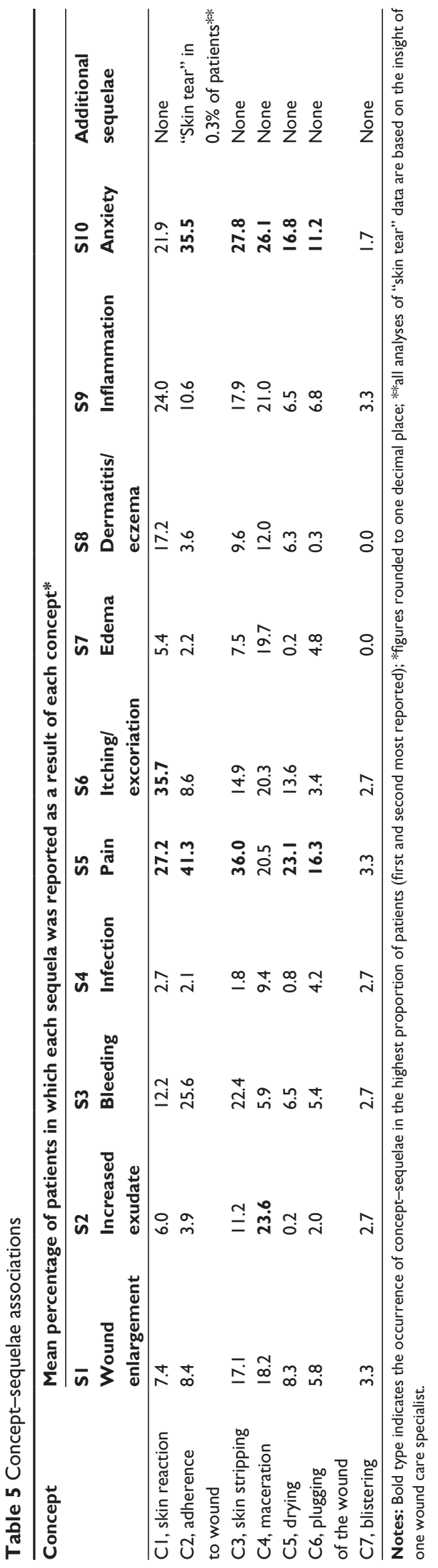


Table 6 Mean total associated cost of HCP time for typical complete onward management of each single occurrence of sequela

\begin{tabular}{|c|c|}
\hline Sequela & HCP costs* \\
\hline Wound enlargement (SI) & $£ \mid 4.22$ \\
\hline Increased exudate (S2) & $£ \mid 4.59$ \\
\hline Bleeding (S3) & $E 10.66$ \\
\hline Infection (S4) & $E 16.05$ \\
\hline Pain (S5) & $E \mid 4.40$ \\
\hline Itching/excoriation (S6) & $f 11.66$ \\
\hline Edema (S7) & $£ 8.74$ \\
\hline Dermatitis/eczema (S8) & $£ 10.64$ \\
\hline Inflammation (S9) & $£ 8.79$ \\
\hline Anxiety (SI0) & $£ \mid 5.14$ \\
\hline
\end{tabular}

Note: *Figures rounded to two decimal places.

Abbreviation: $\mathrm{HCP}$, health care professional.

\section{Pharmaceutical costs}

Complete onward management of each of the ten sequelae was associated with pharmaceutical usage (Table 8). Pharmaceuticals included those elicited in the first phase of the research, ie, analgesia, antihistamines, antimicrobial cream, topical steroids, and antibiotics. In particular, antimicrobial cream and topical steroids were high cost contributors (Table 8). Intravenous antibiotics were not considered a typical treatment for dressing-related trauma by any respondent in this study.

Pharmaceutical costs per sequela were considerably lower than material costs and health care professional time costs. Of the ten main sequelae, infection (S4) was associated with the highest pharmaceutical costs, with antimicrobial cream as the main contributor to costs (Table 8). Wound enlargement (S1), which was associated with the highest material costs (Table 7), was also associated with the second highest pharmaceutical costs (Table 8). The novel sequela, skin tear (S11), was not associated with any pharmaceutical use.

In some instances, wound care specialists provided inconclusive evidence when asked for brand name. For example, free text answers included "gentle analgesia" or "oral analgesia". In these circumstances, the mode answer for that type of intervention was applied (eg, "gentle analgesia" became "paracetamol"). A number of wound care specialists also provided details of additional pharmaceuticals, outside of the previously elicited list. These included "Kaltostat ${ }^{\circledR}$ (ConvaTec, Skillman, NJ, USA) due to bleeding", "Antiseptic soak such as potassium permanganate due to infection", "Oramorph ${ }^{\circledR}$ (Boehringer Ingelheim GmbH, Ingelheim Germany) due to pain and anxiety" and "diuretic (Lasix ${ }^{\circledR}$; Sanofi S.A., Paris, France) due to edema". Kaltostat ${ }^{\circledR}$ was not included within the "other" costs, because this is a type of dressing, and was subsequently included in the material costs. All "others" were included in the pharmaceutical costs per sequela occurrence.

\section{Inpatient management}

The length of inpatient hospitalization for the ten main sequelae ranged from 0.1 to 9 days, with inflammation associated with the longest inpatient duration (Table 9). As shown, the length of stay did not necessarily correlate with frequency of hospitalization (Table 9). Overall, infection (S4) was associated with the highest inpatient management costs. Infection was also associated with the greatest costs associated with health care professional time and pharmaceutical consumption. Skin tear, the novel sequela elicited from one wound care specialist, was not considered to be associated with inpatient hospitalization.

\section{Total sequelae costs}

The sequelae were considered independently of any particular concept to allow for a generalized quantification of each individual sequela. Results show that typical management of the clinical sequela of dressing-related trauma is costly. Total costs, including all of the above direct costs, ranged

Table 7 Mean total material costs for typical complete onward management of each single occurrence of sequela $(n=30)$

\begin{tabular}{|c|c|c|c|c|c|c|c|c|}
\hline Sequela & $\begin{array}{l}\text { Total material } \\
\text { costs }\end{array}$ & $\begin{array}{l}\text { Secondary } \\
\text { dressing* }\end{array}$ & $\begin{array}{l}\text { Skin } \\
\text { barriers* }\end{array}$ & Stockings* & Bandages* & $\begin{array}{l}\text { Gauze } \\
\text { pads* }\end{array}$ & $\begin{array}{l}\text { Disposable } \\
\text { gloves* }\end{array}$ & $\begin{array}{l}\text { Saline } \\
\text { solution* }\end{array}$ \\
\hline Wound enlargement (SI) & $£ 94.66$ & $E 13.16$ & $£ 3.72$ & $£ 30.32$ & $£ 4.32$ & $£ 40.38$ & $£ 2.66$ & $£ 0.10$ \\
\hline Increased exudate (S2) & $£ 77.64$ & $£ \mid 3.86$ & $£ 4.26$ & $E|4.5|$ & $£ 5.26$ & $£ 35.97$ & $£ 3.69$ & $£ 0.09$ \\
\hline Bleeding (S3) & $£ 70.87$ & $£ 9.90$ & $£ 0.43$ & $£ 7.07$ & $£ 4.37$ & $£ 46.30$ & $£ 2.75$ & $£ 0.05$ \\
\hline Infection (S4) & $£ 20.29$ & $£ 6.48$ & $£ 0.89$ & $£ 7.86$ & $£ 1.00$ & $£ 3.66$ & $£ 0.38$ & $£ 0.02$ \\
\hline Pain (S5) & $£ 24.67$ & $£ 7.06$ & $£ 1.97$ & $£ 7.07$ & $£ 0.42$ & $£ 6.51$ & $£ 1.57$ & $£ 0.06$ \\
\hline Itching/excoriation (S6) & $£ 24.68$ & $£ 2.29$ & $£ 4.21$ & $£ \mid 0.22$ & $£ 0.91$ & $£ 6.05$ & $£ 0.99$ & $£ 0.01$ \\
\hline Edema (S7) & $£ 32.57$ & $£ 4.95$ & $£ 0.32$ & $£ \mid 8.86$ & $£ 2.34$ & $£ 4.89$ & $£ 1.20$ & $£ 0.02$ \\
\hline Dermatitis/eczema (S8) & $£ 33.31$ & $£ 4.22$ & $£ 6.21$ & $£ 17.69$ & $£|.5|$ & $£ 2.49$ & $£ 1.17$ & $£ 0.02$ \\
\hline Inflammation (S9) & $£ 18.35$ & $£ 5.09$ & $£ 0.88$ & $£ 9.61$ & $£ 0.84$ & $£ 1.55$ & $£ 0.36$ & $£ 0.02$ \\
\hline Anxiety (SI0) & $£ 8.35$ & $£ 3.22$ & $£ 0.35$ & $£ 3.25$ & $£ 0.20$ & $£ 0.96$ & $£ 0.33$ & $£ 0.03$ \\
\hline
\end{tabular}

Note: *Figures rounded to two decimal places. 
Table 8 Mean total pharmaceutical costs for complete onward management of each single occurrence of sequela $(n=30)$

\begin{tabular}{|c|c|c|c|c|c|c|c|c|}
\hline Sequela & $\begin{array}{l}\text { Total } \\
\text { pharmaceutical } \\
\text { costs }\end{array}$ & Analgesia* & Antihistamines* & $\begin{array}{l}\text { Antimicrobial } \\
\text { cream* }\end{array}$ & $\begin{array}{l}\text { Topical } \\
\text { steroids* }\end{array}$ & $\begin{array}{l}\text { Antibiotics } \\
\text { (oral)* }\end{array}$ & $\begin{array}{l}\text { Antibiotics } \\
\text { (IV)* }\end{array}$ & Other* \\
\hline $\begin{array}{l}\text { Wound } \\
\text { enlargement (SI) }\end{array}$ & $E \mid 3.98$ & $£ 0.31$ & $£ 0.00$ & $£ 10.77$ & $£ 2.41$ & $£ 0.49$ & $£ 0.00$ & $£ 0.00$ \\
\hline Increased exudate (S2) & $£ 0.32$ & $£ 0.13$ & $£ 0.00$ & $£ 0.00$ & $£ 0.00$ & $£ 0.19$ & $£ 0.00$ & $£ 0.00$ \\
\hline Bleeding (S3) & $£ 0.08$ & $£ 0.08$ & $£ 0.00$ & $£ 0.00$ & $£ 0.00$ & $£ 0.00$ & $£ 0.00$ & $£ 0.00$ \\
\hline Infection (S4) & $£ 15.03$ & $£ 0.22$ & $£ 0.00$ & $f|2.2|$ & $£ 0.00$ & $£ 2.60$ & $£ 0.00$ & $£ 0.00$ \\
\hline Pain (S5) & $£ 0.78$ & $£ 0.63$ & $£ 0.00$ & $£ 0.00$ & $£ 0.00$ & $£ 0.06$ & $£ 0.00$ & $£ 0.10$ \\
\hline Itching/excoriation (S6) & $£ 8.02$ & $£ 0.11$ & $£ 2.37$ & $£ 0.00$ & $£ 5.54$ & $£ 0.00$ & $£ 0.00$ & $£ 0.00$ \\
\hline Edema (S7) & $£ 10.06$ & $£ 0.05$ & $£ 0.01$ & $£ 0.00$ & $£ 0.00$ & $£ 0.00$ & $£ 0.00$ & $£ 10.00$ \\
\hline Dermatitis/eczema (S8) & $f \mid 2.08$ & $£ 0.06$ & $£ 0.20$ & $£ 0.00$ & $f|| .83$ & $£ 0.00$ & $£ 0.00$ & $£ 0.00$ \\
\hline Inflammation (S9) & $f \mid .81$ & $£ 0.17$ & $£ 0.06$ & $£ 0.00$ & $£ 1.46$ & $£ 0.13$ & $£ 0.00$ & $£ 0.00$ \\
\hline Anxiety $(S \mid 0)$ & $£ 0.20$ & $£ 0.10$ & $£ 0.00$ & $£ 0.00$ & $£ 0.00$ & $£ 0.00$ & $£ 0.00$ & $£ 0.10$ \\
\hline
\end{tabular}

Notes: *Figures rounded to two decimal places; “other” includes antiseptic soak, Oramorph ${ }^{\circledR}$ (Boehringer Ingelheim GmbH, Ingelheim, Germany), and diuretic. Abbreviation: IV, intravenous.

from $£ 23.73$ to $£ 208.48$ per single sequela occurrence (including the ten main sequelae, Figure 6). Infection (S4) was associated with the highest costs and anxiety (S10) was associated with the lowest costs. For the novel sequela, skin tear, elicited from one wound care specialist, complete onward management costs were $£ 25.46$ (data not shown). For the majority of sequelae, inpatient management and material usage were the largest contributors to the overall direct costs (Figure 6). The exceptions were "itching" and "anxiety", where health care professional time and materials were the largest contributors to the cost burden.

\section{Expected costs per concept occurrence}

The expected cost of each sequela was then multiplied by the probability of sequela occurrence within a particular

Table 9 Mean total inpatient costs for complete onward management of each single occurrence of sequela $(n=30)$

\begin{tabular}{|c|c|c|c|}
\hline Sequela & $\begin{array}{l}\text { Total } \\
\text { inpatient } \\
\text { costs* }\end{array}$ & $\begin{array}{l}\text { Proportion of } \\
\text { patients requiring } \\
\text { inpatient } \\
\text { management (\%) }\end{array}$ & $\begin{array}{l}\text { Length of } \\
\text { inpatient } \\
\text { hospitalization } \\
\text { (days) }\end{array}$ \\
\hline $\begin{array}{l}\text { Wound } \\
\text { enlargement (SI) }\end{array}$ & $£ 48.32$ & $3.6 \%$ & 5.1 \\
\hline $\begin{array}{l}\text { Increased } \\
\text { exudate (S2) }\end{array}$ & $£|0| .38$ & $6.9 \%$ & 5.6 \\
\hline Bleeding (S3) & $£ 31.68$ & $2.0 \%$ & 6.0 \\
\hline Infection (S4) & f|57.II & $7.2 \%$ & 8.2 \\
\hline Pain (S5) & $£ 50.49$ & $2.8 \%$ & 6.8 \\
\hline $\begin{array}{l}\text { Itching/ } \\
\text { excoriation (S6) }\end{array}$ & $£ 3.96$ & $0.3 \%$ & 4.5 \\
\hline Edema (S7) & $£ 31.19$ & $2.3 \%$ & 5.3 \\
\hline $\begin{array}{l}\text { Dermatitis/ } \\
\text { eczema (S8) }\end{array}$ & $£ 23.10$ & $1.3 \%$ & 7.0 \\
\hline Inflammation (S9) & $£ 27.28$ & $1.1 \%$ & 9.0 \\
\hline Anxiety (SI0) & $£ 0.03$ & $0.2 \%$ & 0.1 \\
\hline
\end{tabular}

Note: *Figures rounded to two decimal places. concept (Table 5). The costs were then added together within a concept, to provide a typical cost per concept occurrence. Results show that the mean total costs ranged from $£ 56$ to $£ 175$ for complete onward management of each occurrence of the original six concepts (Table 10). The expected costs for the novel concept, blistering, were $£ 31$ per occurrence.

To put these data into context, a typical case of wound maceration could cost $£ 175$ due to the resource use associated with management of the sequelae. It is not possible to calculate the costs of a full traumatic event, with multiple trauma concepts, due to the considerable heterogeneity and complexity of dressing-related trauma (ie, overlap of sequelae and management).

The mean total and component costs (consumables, inpatient management, and health care professional time) of each concept are shown in Figure 7. Inpatient management and material usage represent the largest contributors to the overall direct costs of dressing-related trauma.

\section{Discussion}

The overall objectives of this research were to explore the concept of dressing-related trauma and to attempt to quantify the associated costs. This research has categorized dressingrelated trauma, identified a number of associated clinical sequelae, and quantified (albeit in a limited population) the average resource utilization associated with a typical occurrence of each trauma concept. Subsequent allocation of costs has given an indication of the possible cost of dressing-related trauma.

The findings from this study demonstrate that dressingrelated trauma is a clinically relevant and troublesome concept, with all 30 wound care specialists reporting that the wearing and removal of a dressing can have traumatic consequences. 


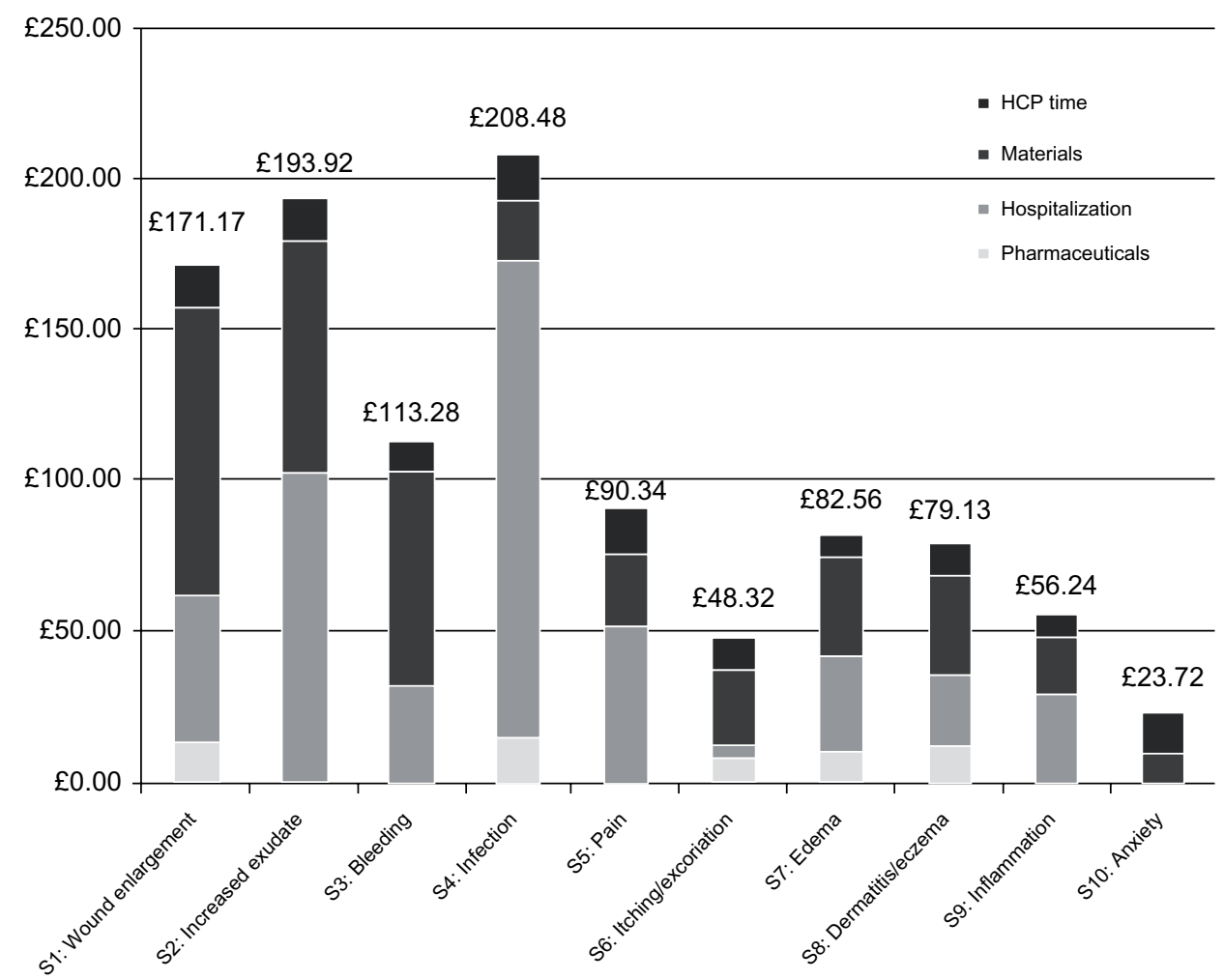

Figure 6 Mean total costs for the typical complete onward management of each single occurrence of the sequela $(n=30)$. Abbreviation: $\mathrm{HCP}$, health care provider.

The main types of dressing-related trauma, defined as concepts, included skin reactions, adherence to the wound, skin stripping, maceration, drying, and plugging of the wound. These concepts were the foundation for a number of clinical sequelae, including wound enlargement, increased exudate, bleeding, infection, pain, itching/excoriation, edema, dermatitis, inflammation, and anxiety. All of the ten main sequelae were associated with each of the original concepts.

The quantitative results of this study show that the management of dressing-related trauma incurs health care professional time, consumables (materials and pharmaceuticals), and inpatient management costs. Generally, material and inpatient management costs were the largest contributors to the direct cost burden for any of the trauma concepts.

There are some limitations to this research, including the small sample size $(n=30)$ and the exploratory approach based

Table 10 Mean total costs for complete onward management of each single occurrence of trauma concept $(n=30)$

\begin{tabular}{ll}
\hline Concept (in descending cost order) & Expected cost $(\mathbf{n}=\mathbf{3 0})$ \\
\hline Maceration (C4) & $£ 175$ \\
Skin stripping/shearing (C3) & $£ 150$ \\
Skin reaction (CI) & $£ 122$ \\
Adherence to wound (C2) & $£ 116$ \\
Drying (C5) & $£ 64$ \\
Plugging of the wound (C6) & $£ 56$ \\
\hline
\end{tabular}

on expert opinion. The study was not powered to calculate statistical significance, and further research using a larger sample size is required to confirm the findings of this study. Despite these limitations, the results provide insight into the, until now, hidden costs of dressing-related trauma management and the ratio of the cost components by trauma type. The findings of this study are relevant because they highlight the wider cost considerations for wound care management beyond the unit cost of the dressing. For example, the costs associated with secondary dressings are estimated at $£ 13.16$ for complete onward management of a single occurrence of "wound enlargement". This was $<8 \%$ of the total cost of $£ 171.17$ for wound enlargement, which also included costs related to other materials, pharmaceuticals, health care professional time, and inpatient management. Published data also support these assumptions, as estimated costs of wound care treatment were $£ 2.3-3.1$ billion per year (at 2005-2006 costs) ${ }^{23}$ however, the reported cost of wound dressings is only a minor proportion of this cost. ${ }^{24}$

Recent National Health Service publications suggest that appropriate treatment options, including optimal dressing selection, may avoid the high incidence of clinical sequelae and associated resource use. ${ }^{24}$ Initiatives relating to optimal wound dressings have led to the development of an "ideal" wound dressing (or dressing system) formula, which should: ${ }^{5}$ 


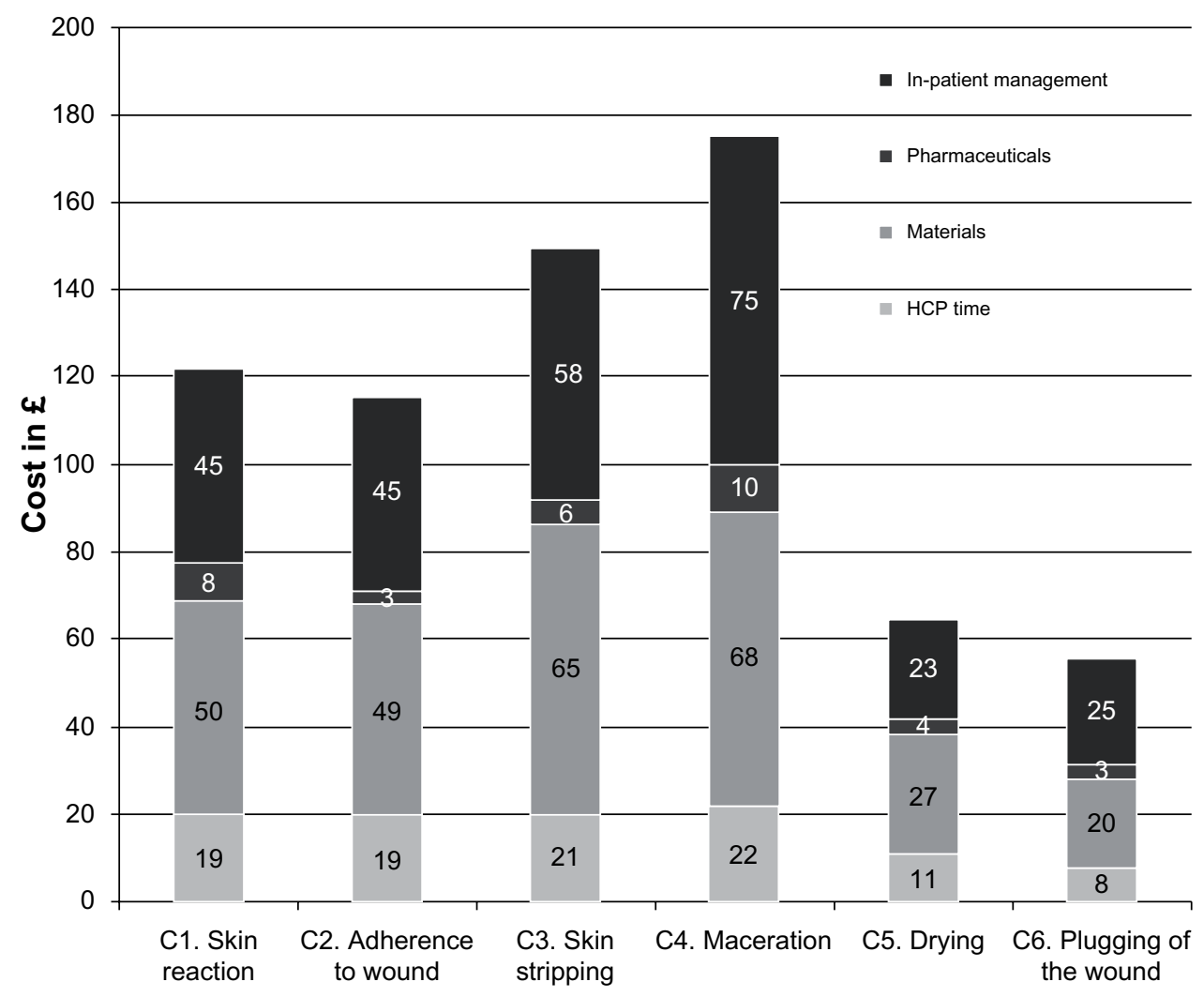

Figure 7 Component costs of mean total costs for the complete onward management of each single occurrence of the concepts ( $\mathrm{n}=30$ ). Abbreviation: HCP, health care provider.

- create an ideal microclimate for rapid and effective healing

- prevent dehydration and be permeable to oxygen

- provide good absorption of blood and exudate

- protect against secondary infection and sufficient mechanical protection to the wound

- be nonadherent and not shed loose material into wound

- conform to anatomical contours.

Atraumatic dressings have been developed to take account of these factors and effectively overcome the problems of adherence to the wound and damage to the surrounding skin. ${ }^{5}$ A case study, reported in a public policy document from Canada, demonstrates the cost savings that can be gained through optimal wound care management and dressing selection. ${ }^{25}$

Multiple factors can prevent wounds from healing in the expected time frame; however, this study does not investigate inappropriate wound management after patient discharge or the impact of comorbidities, poor nutrition, medication, or altered body functions on wound healing. ${ }^{2}$

The results of this exploratory research provide insight into the hidden costs of dressing-related trauma in a UK setting. The results of this research and other such studies may lead to a better understanding of the real costs of wound care, enhanced decision-making, and ultimately increased patient satisfaction. Further research in the area of dressingrelated trauma and the associated costs are warranted.

\section{Disclosure}

The authors did not have any assistance with the study design or data analysis. Data collection in the second phase of the research was conducted by Medefield UK. Medefield is a provider of online fieldwork services to pharmaceutical market research, consulting, and health care communication agencies. Editorial support was provided by Adelphi Values. $\mathrm{BC}$ and $\mathrm{CP}$ are employed by Adelphi Values UK. PC and MB have not received honoraria as part of this piece of work; however, both have received honoraria from Mölnlycke Health Care for earlier work. This study was funded by Mölnlycke Health Care.

\section{References}

1. Jones SM, Banwell PE, Shakespeare PG. Advances in wound healing: topical negative pressure therapy. Postgrad Med J. 2005;81(956): 353-357.

2. Royal Children's Hospital. The Royal Children's Hospital Clinical Guidelines: Nursing Wound Care. 2012-2013, Parkville, Australia: Clinical Effectiveness Committee; 2013. Available from: http://www.rch.org. au/rchcpg/hospital_clinical_guideline_index/Wound_care/. Accessed February 23, 2014. 
3. American Pediatric Surgical Nurses Association. Wound care principles and products. Available from: http://www.apsna.org/-wound-care. Accessed September 18, 2013.

4. Chaby G, Senet P, Vaneau M, et al. Dressings for acute and chronic wounds: a systematic review. Arch Dermatol. 2007;143(10):1297-1304.

5. Thomas S. Atraumatic dressings. World Wide Wounds; 2003. Available from: http://www.worldwidewounds.com/2003/january/Thomas/ Atraumatic-Dressings.html. Accessed February 23, 2014.

6. White R. A multinational survey of the assessment of pain when removing dressing. Wounds UK, 2008;4(1). Available from: http://www. molnlycke.com/Documents/GLOBAL\%20-\%20ENG/Wound\%20 Care/R-White-2008-multniational-survey.pdf. Accessed February 23, 2014.

7. World Union of Wound Healing Societies. Principles of Best Practice: Minimising Pain At Wound Dressing-Related Procedures. A Consensus Document. Toronto, Canada: WoundPedia Inc; 2007. Available from: http://www.molnlycke.com/Old/Global/NewsAndEvents_Local/ CA-EN/Best_Practice.pdf. Accessed February 24, 2013.

8. European Wound Management Association. Position Document: Pain at wound dressing change. Available from: http://ewma.org/fileadmin/ user_upload/EWMA/pdf/Position_Documents/2002/Spring_2002_ English_.pdf. Accessed February 23, 2014.

9. Moffat CJ, Franks PJ, Hollingworth H. Understanding wound pain and trauma: an international perspective. In: European Wound Management Association Position Document. Pain at Wound Dressing Changes. London, UK: Medical Education Partnership; 2002.

10. Dykes PJ, Heggie R. The link between the peel force of adhesive dressings and subjective discomfort in volunteer subjects. $J$ Wound Care. 2003;12(7):260-262.

11. Cutting KF. Impact of adhesive surgical tape and wound dressings on the skin, with reference to skin stripping. J Wound Care. 2008;17(4): 157-158, 160-162.

12. Davies P, Rippon M. Comparison of foam and hydrocolloid dressings in the management of wounds: a review of the published literature. World Wide Wounds, 2010. Available from: http://www.worldwidewounds. com/2010/July/DaviesRippon/DaviesRippon.html. Accessed February 23, 2014.

13. Peters D. Simple changes in wound trauma management yield significant benefits for everyone, 2008. Available from: http://www. hollisterwoundcare.com/files/pdfs/posters/PetersPoster_910487.pdf. Accessed February 23, 2014.

14. Posnett J, Franks PJ. The burden of chronic wounds in the UK. Nursing Times. 2008;104(3):44-45.
15. Rippon M, Davies P, White R, Bosanquet N. Cost implications of using an atraumatic dressing in the treatment of acute wounds. JWound Care. 2008;17(5):224-227.

16. Wright K. Researching Internet-based populations: advantages and disadvantages of online research, online questionnaire authoring software packages and web survey services. Journal of Computer-Mediated Communication. 2006;10(3). Available from: http://onlinelibrary.wiley. com/doi/10.1111/j.1083-6101.2005.tb00259.x/full. Accessed February 23, 2014.

17. British Healthcare Business Intelligence Association. Legal and Ethical Guidelines for Healthcare Market Research. 2011. Available from: http:// www.bhbia.org.uk/guidelines/legalandethicalguidelines.aspx. Accessed March 26, 2014

18. Curtis L. Unit costs of health and social care. Canterbury, UK: Personal Social Services Research Unit; 2010. Available from: http://kar.kent. ac.uk/32408/1/full-with-covers.pdf. Accessed February 23, 2014.

19. Journal of Wound Care. The Wound Care Handbook 2013. Available from: http://www.woundcarehandbook.com. Accessed April 23, 2013.

20. BMJ and RPSGB, British National Formulary. Available from: http:// www.bnf.org/bnf/index.htm. Accessed April 23, 2013.

21. Department of Health. Reference costs 2011-2012. Available from: http:/www.gov.uk/government/uploads/system/uploads/attachment_ data/file/127112/2011-12-reference-costs-publication.pdf.pdf. Accessed April 23, 2013.

22. National Association of Clinical Nurse Specialists. White paper on certification of clinical nurse specialists. 2005. Available from: http:// www.nacns.org/docs/PaperOnCertCNS.pdf. Accessed February 23, 2014.

23. Posnett J, Franks P. The burden of chronic wounds in the UK. Nursing Times. 2008;104(3):44-45.

24. National Prescribing Centre. Evidence-based prescribing of advanced wound dressings for chronic wounds in primary care. London, UK: MeReC Publication, 2010. Available from: http://www.npc.nhs. uk/merec/therap/wound/merec_bulletin_vol21_no1.php. Accessed February 23, 2014.

25. Teague LM, Mahoney JL. Cost-effective wound care: how the advanced practice nursing role can positively affect outcomes in an acute-care setting. Public Policy Document Wound Care Canada. Available from: http://cawc.net/images/uploads/wcc/2-1-Teague_V2_Iss1.pdf. Accessed March 26, 2014.
ClinicoEconomics and Outcomes Research

\section{Publish your work in this journal}

ClinicoEconomics \& Outcomes Research is an international, peerreviewed open-access journal focusing on Health Technology Assessment, Pharmacoeconomics and Outcomes Research in the areas of diagnosis, medical devices, and clinical, surgical and pharmacological intervention. The economic impact of health policy and health systems

\section{Dovepress}

organization also constitute important areas of coverage. The manuscript management system is completely online and includes a very quick and fair peer-review system, which is all easy to use. Visit http://www.dovepress.com/testimonials.php to read real quotes from published authors. 